\title{
Is There a (Data) Point? Are All of These Measures Useful?
}

\author{
Joseph Hafner, Dawn McKinnon, Martin Morris, and Andrew Senior \\ McGill University, Canada
}

\section{Introduction}

Collection evaluation is time consuming, and collaboration between collection librarians and liaison librarians can lead to more meaningful assessment and context of usage of library resources. Each collection assessment tool offers a unique perspective and comes with its own set of advantages and disadvantages for different types of collections, subjects and ease of use. It can be overwhelming to select a tool and find time to use it to its full potential in order to fully evaluate a collection.

While COUNTER statistics have become one standard that captures usage of electronic journals ("ejournals"), many libraries look for additional data to help assess how their collections are used, to add depth to the analysis. Citation analysis, for instance, is another way that libraries can count usage, as it is considered a standard and valid measure. ${ }^{1}$ A project described by De Groote, Blecic, and Martin is a good example where local citation data was combined with COUNTER statistics and data from their link resolver to get a better understanding of usage. ${ }^{2}$ Citation data can be pulled from databases like Web of Science or Scopus, ${ }^{3}$ and indexing companies like Clarivate (formerly Thomson Reuters) also sell their data to be analyzed. ${ }^{4}$

At McGill University Library, collection services librarians collaborated with liaison librarians to gather data from multiple sources, including a yearlong ARL MINES for Libraries survey (https://www.arl.org/focusareas/statistics-assessment/mines-for-libraries), 1Science reports comparing usage and faculty citation data against the library's holdings, results from faculty surveys on their preferred journals for teaching, as well as traditional vendor-supplied statistics.

Of the 40,000 students attending McGill University, 252 are part of the Faculty of Dentistry. The bulk of these students are undergraduates (153), and the remaining consist of residents and fellows (28), master's students (38), doctoral students (25), and postdoc students (8). ${ }^{5}$ In these proceedings, data from the Faculty of Dentistry is used as an example to showcase what can be learned by combining data from multiple tools.

\section{Research Questions}

To gain a deep understanding of how faculty and students use e-journal collections to help inform collection development and promotion, the tools mentioned above were used to examine the following research questions:

- Which e-journals were being used, and by whom?

- Are the journals that faculty cite and publish in the same journals being downloaded the most often? What kind of coverage does the library provide to these e-journals?

- How do results of "priority" or "top" e-journals differ depending on the measurement tool used?

- Do some of the tools provide more comprehensive information for different subject areas? Is one type of tool better for certain tasks or questions?

\section{Methodology}

This analysis makes use of the data sources described below. The list of journals was retrieved from Scopus using the "Sources" database. There were a total of 238 journals in the listing.

Data were analyzed in R (version 3.5.1) ${ }^{6}$ within RStudio (version 1.1.462). ${ }^{7}$ 
MINES for Libraries (Measuring the Impact of Networked Electronic Services) is an online survey protocol from the Association of Research Libraries (ARL) (https://www.arl.org/resources/mines-for-libraries-finalreport/). The protocol allows libraries to create customized online surveys, configured to pop-up when a patron clicks on an e-resource from the library catalogue or discovery system. Libraries work with ARL to determine the optimal configuration and timing of the survey, depending on the library's needs. For example, the survey can be set up to run for a short time, such as a single day or a week, and appear every time an e-resource link is selected. Alternatively, it can be run for a longer period, such as a year, and configured to pop up every $n t h$ time an e-resource is selected. At McGill, it was configured through the EZproxy settings and appeared every 200th time an e-resource was accessed. ARL suggested this timing as a way to collect enough data points over time without being too disruptive to library patrons. The survey ran for a year, starting in September 2015.

The Journal Usage Project (JUP) was an online survey conducted with faculty across Canada, administered by the Canadian Research Knowledge Network (CRKN), a Canadian consortium for licensing content (https://www.crkn-rcdr.ca/en/journal-usage-project). Each participating institution had to obtain approval from its ethics board. The survey asked teaching professors to specify top journals they prefer for teaching and research. When a journal was indicated by a professor as being a "top" journal, it was considered a "mention" in the survey results. For example, if three professors wrote that a journal was their top choice, that journal had " 3 mentions" in the results. The researchers combined the survey results with usage data pulled from Web of Science, including article downloads, as well as the number of faculty publications and citations within a given journal. At McGill University, this survey was sent out in January 2017 and ran for six weeks.

1Science created a custom report specific to the library's requests, on data pulled from Web of Science covering 2006-2015. The report included article downloads, as well as the number of publications written and/or cited by McGill faculty and indexed in Web of Science during that time period.

\section{Results \\ MINES}

The MINES survey resulted in 4,413 responses, with 47 (1.07\%) participants self-identifying as being part of the Faculty of Dentistry. Within this group, the subset with the most participants was graduate students, as shown in Table 1 . The MINES survey asked the participants to identify the location from where they were accessing the library e-resource. The undergraduate and graduate students indicated they were off-campus, while the residents indicated they were in a McGill-affiliated hospital, as shown below. 
Table 1: MINES participants in the Faculty of Dentistry, by location

\begin{tabular}{|c|c|c|c|c|c|}
\hline & Off-campus & $\begin{array}{l}\text { On campus } \\
\text { (library) }\end{array}$ & $\begin{array}{l}\text { On campus } \\
\text { (not library) }\end{array}$ & $\begin{array}{c}\text { McGill-affiliated } \\
\text { hospital }\end{array}$ & Total \\
\hline Undergraduate & 5 & 3 & 3 & 0 & 11 \\
\hline Graduate & 16 & 2 & 3 & 0 & 21 \\
\hline Post-doc & 0 & 0 & 1 & 1 & 2 \\
\hline Resident & 1 & 0 & 0 & 4 & 5 \\
\hline Faculty & 1 & 1 & 1 & 2 & 5 \\
\hline Research staff & 0 & 0 & 1 & 0 & 1 \\
\hline Other & 0 & 1 & 0 & 0 & 1 \\
\hline
\end{tabular}

One of the primary reasons that libraries use MINES is to survey the patron's purpose for selecting an eresource, such as whether the item will be used for an assignment or for writing a thesis, as well as the reason why they selected the specific e-resource, such as a librarian recommended it or it was an important resource in the field. For the Faculty of Dentistry participants, the top two purposes selected were thesis/dissertation with 14/47 participants (29.8\%) and coursework/assignment with 12/47 participants (25.5\%). The highest result selected as the "reason" for choosing the specific e-resource was "important resource in my field," with $27 / 47$ (57.4\%) participants.

\section{Journal Usage Project}

As shown in Table 2, each measurement results in a different "top" journal for the JUP. For example, the Journal of the American Dental Association was the top journal mentioned by faculty, yet it was $19^{\text {th }}$ in the top downloads for 2015 .

Table 2: JUP top results

\begin{tabular}{|l|l|l|}
\hline \multicolumn{1}{|c|}{ Top downloads (2015) } & \multicolumn{1}{|c|}{$\begin{array}{c}\text { Top downloads } \\
\text { (Average 2011-2015) }\end{array}$} & \multicolumn{1}{|c|}{ Top mentions (faculty) } \\
\hline Journal of Endodontics & $\begin{array}{l}\text { Journal of Oral and Maxillofacial } \\
\text { Surgery }\end{array}$ & $\begin{array}{l}\text { Journal of the American Dental } \\
\text { Association }\end{array}$ \\
\hline $\begin{array}{l}\text { Journal of Oral and Maxillofacial } \\
\text { Surgery }\end{array}$ & Journal of Endodontics & $\begin{array}{l}\text { International Journal of Dental } \\
\text { Research }\end{array}$ \\
\hline Journal of Prosthetic Dentistry & Journal of Prosthetic Dentistry & Journal of Dental Research \\
\hline Journal of Dental Research & $\begin{array}{l}\text { American Journal of Orthodontics } \\
\text { and Dentofacial Orthopedics }\end{array}$ & Oral Oncology \\
\hline
\end{tabular}




\begin{tabular}{|c|c|c|}
\hline Top downloads (2015) & $\begin{array}{l}\text { Top downloads } \\
\text { (Average 2011-2015) }\end{array}$ & Top mentions (faculty) \\
\hline Dental Materials & Journal of Dental Research & Journal of Public Health Dentistry \\
\hline Australian Dental Journal & Journal of Clinical Periodontology & Special Care in Dentistry \\
\hline Dental Clinics of North America & Journal of Dentistry & Implant Dentistry \\
\hline International Endodontic Journal & Clinical Oral Implants Research & Gerodontology \\
\hline Journal of Clinical Periodontology & International Endodontic Journal & $\begin{array}{l}\text { JDR Clinical \&t Translational } \\
\text { Research }\end{array}$ \\
\hline $\begin{array}{l}\text { American Journal of Orthodontics } \\
\text { and Dentofacial Orthopedics }\end{array}$ & Journal of Oral Rehabilitation & Australian Dental Journal \\
\hline Journal of Dentistry & Dental Clinics of North America & Journal of Dental Education \\
\hline $\begin{array}{l}\text { International Journal of Oral and } \\
\text { Maxillofacial Surgery }\end{array}$ & Oral Oncology & Community Dental Health \\
\hline $\begin{array}{l}\text { Oral and Maxillofacial Surgery } \\
\text { Clinics of North America }\end{array}$ & Journal of Periodontal Research & Journal of Dentistry \\
\hline Clinical Oral Implants Research & $\begin{array}{l}\text { International Journal of Oral and } \\
\text { Maxillofacial Surgery }\end{array}$ & California Dental Journal \\
\hline Oral Oncology & $\begin{array}{l}\text { Journal of Oral Pathology \& } \\
\text { Medicine }\end{array}$ & $\begin{array}{l}\text { Journal of the Canadian Dental } \\
\text { Association }\end{array}$ \\
\hline $\begin{array}{l}\text { British Journal of Oral and } \\
\text { Maxillofacial Surgery }\end{array}$ & $\begin{array}{l}\text { Oral Surgery Oral Medicine Oral } \\
\text { Pathology Oral Radiology and } \\
\text { Endodontology }\end{array}$ & \\
\hline $\begin{array}{l}\text { Oral Surgery, Oral Medicine, Oral } \\
\text { Pathology and Oral Radiology }\end{array}$ & $\begin{array}{l}\text { Oral and Maxillofacial Surgery } \\
\text { Clinics of North America }\end{array}$ & \\
\hline $\begin{array}{l}\text { Journal of the American Dental } \\
\text { Association }\end{array}$ & $\begin{array}{l}\text { British Journal of Oral and } \\
\text { Maxillofacial Surgery }\end{array}$ & \\
\hline \multirow[t]{2}{*}{$\begin{array}{l}\text { Journal of Cranio-Maxillofacial } \\
\text { Surgery }\end{array}$} & Dental Materials & \\
\hline & Journal of Public Health Dentistry & \\
\hline
\end{tabular}


Combining results from the 1Science report with the JUP "faculty mentions" and journals in which faculty publish shows even more differences for the "top" journal as shown in Table 3.

Table 3: Combination of 1Science report with JUP results

\begin{tabular}{|c|c|c|c|}
\hline Journal & $\begin{array}{c}\text { Top downloads } \\
\text { (2015) }\end{array}$ & Mentions & $\begin{array}{c}\text { Faculty } \\
\text { publications }\end{array}$ \\
\hline Australian Dental Journal & 1223 & 2 & 0 \\
\hline California Dental Journal & $N / A$ & 1 & 0 \\
\hline Community Dental Health & $N / A$ & 2 & 2 \\
\hline Dental Clinics of North America & 1175 & 0 & 0 \\
\hline Dental Materials & 1285 & 0 & 0 \\
\hline Gerodontology & $N / A$ & $N / A$ & 1 \\
\hline Implant Dentistry & 382 & 2 & 0 \\
\hline International Endodontic Journal & 1188 & 0 & 0 \\
\hline International Journal of Dental Research & $N / A$ & 4 & 0 \\
\hline JDR Clinical and Translational Research & $N / A$ & 2 & 0 \\
\hline Journal of Clinical Periodontology & 1105 & 0 & 3 \\
\hline Journal of Dental Education & $N / A$ & $N / A$ & 8 \\
\hline Journal of Dental Research & 1437 & 4 & 23 \\
\hline Journal of Dentistry & 1062 & 1 & 4 \\
\hline Journal of Endodontics & 4401 & 0 & 0 \\
\hline Journal of Oral and Maxillofacial Surgery & 2386 & 0 & 1 \\
\hline Journal of Oral Rehabilitation & 567 & 1 & 2 \\
\hline Journal of Periodontal Research & 207 & 0 & 0 \\
\hline Journal of Prosthetic Dentistry & 1675 & 0 & 0 \\
\hline Journal of the American Dental Association & 651 & 5 & 0 \\
\hline Journal of the Canadian Dental Association & 0 & 1 & 5 \\
\hline Oral Oncology & 11 & 1 & 1 \\
\hline Special Care in Dentistry & 198 & 2 & 0 \\
\hline
\end{tabular}

Comparing data from different measurement tools allows for deeper analysis and requires a knowledge of the subject area. The Journal of Dental Research ranks high for all measures-downloads, "mentions," and publications. Also, the Journal of the American Dental Association was a top "mentioned" journal by the faculty in the JUP, but it was not the top journal according to faculty publications and downloads. However, the download data for some journals is suspect due to the way it was pulled and input errors, and requires further analysis. Special Care Dentistry was mentioned twice by faculty as being important, yet the data 
shows that McGill faculty has not published in this journal. The Journal of Dental Education is an important journal within the faculty, but it was not in JUP data.

\section{Discussion}

The results highlight a frequent mismatch between faculty opinions of significant journals in their field, and journals that are downloaded. Journals appeared to fall into one of three classes:

1. Journals where usage data matches with faculty perspectives. For example, the Journal of Dental Research has many downloads, is popular for faculty publications, and has many "mentions" as a top journal.

2. Journals with many downloads, but faculty appear to believe the journal is less significant; for example Journal of Oral and Maxillofacial Surgery.

3. Journals which appear to seem important to faculty, but where this popularity is not borne out by downloads or publications; for example Special Care Dentistry.

This clearly demonstrates that when using these types of tools to assess a collection, one must fully understand the advantages of the tool as well as its bias and limitations. Whenever possible, it is best to use multiple tools before making decisions. Fortunately for the McGill Library, regardless of the tool, the library had full or recent coverage of all of the e-journals considered as "top journals."

Not surprisingly, findings show that each tool has advantages and challenges. One disadvantage of the 1Science report and the JUP data is their reliance on Web of Science. Web of Science is popular for these types of data pulls. However, it is not exhaustive, and many journals used by the library's patrons are not indexed in the Web of Science, and therefore excluded from this type of analysis. While this paper uses the field of dentistry as an example, the full research project covered other subjects and, predictably, Web of Science was found to include more of the journals analyzed for the physical and health sciences than for the arts and humanities subjects. This should be kept in mind when selecting a tool that relies on Web of Science data.

Similarly, many popular journals for dentistry are not included in this analysis, as they are not categorized as dental journals. Journals used by the faculty can be in various categories, such as health, biomedical, psychology, etc. 1Science, in particular, has grouped journals by subject and, in doing so, may result in an incomplete picture of the faculty publications. Another future step in analyzing the collection could be to pull a composite list of dental journals and then reverse-lookup the titles in the various tools, regardless of the category that the tool uses.

None of these tools captured access to open access journals. Many fields, including dentistry, have one or two key journals that are open access. Individual title analysis is sometimes possible using COUNTER data, but having to rely on pulling each title separately is extremely time-consuming. As open access becomes increasingly important, it will become important for these types of assessment tools to find ways to capture usage of these titles.

Whenever collecting usage data, considering the time period is essential. As much of this data for these tools ended with 2015, some current journals are missing or the usage data is quite different. This could be due to changes in the journal content or how the journal is accessed, which is reflected in the usage data. For example, the Journal of the American Dental Association is accessed differently than it was in 2015, so usage data for more recent time periods are different than they were in 2015.

The results of the MINES survey offered a different perspective than the other tools, and provided insight into how some people are using the library's electronic resources. Like any tool, one must consider the context and composition of the faculty being analyzed is especially important when using MINES data. The 
data collected for the Faculty of Dentistry showed that the highest portion of participants were graduate students. The primary purpose for these participants was "thesis/dissertation," which is consistent with participants who indicated they are graduate students. However, the faculty consists of $61 \%$ undergraduate students, demonstrating an inconsistency between the composition of the survey participants and the makeup of the faculty's student population. Given the low sample size for this faculty, further studies are needed to make conclusions. While not representative of the faculty, it can still be useful data. For example, the library can now investigate further within the faculty to determine if and how undergraduates and graduates are using the library differently. When speaking with graduate students within the faculty, the liaison librarian can focus finding resources for theses and dissertations, knowing that some students indicated this was the purpose for using the library.

The project highlighted that a single tool or single data source was not shown to be generally "better" than another, and one data source does not provide the entire picture. Using a combination of faculty feedback alongside usage provides more reliable data and helps librarians better understand the collection. As trends change, ongoing sampling and bibliometric analysis would be beneficial.

\section{Limitations}

There are several limitations in this research project. Regarding the MINES data, results are based on a small sample that was shown not to be representative of the faculty composition. To gain this type of insight into just the Faculty of Dentistry, further research would be needed in order to make conclusions.

Source data were taken at different times (JUP faculty survey was in 2017, Web of Science data was from 2015, the 1Science report was provided 2015, and MINES was conducted 2015-2016). Results are indicative of interesting trends in collections usage for this particular discipline, but should be interpreted with caution. The date range of the source data provides a broader picture of collection usage trends; however, different data from different source dates were compared.

Some of the data pulled by the tools was incorrect due to how the data pull was set up, resulting in inconsistent download data. For example, the JUP and 1Science both pulled from Web of Science in 2015 but some titles had different values for the same measurement (article downloads). It was discovered later that this was due to how the data was pulled.

Additionally, download data for open access journals was not considered, as they were not captured by the tools used in this project. This creates the risk of missing significant information on open access journals such as BMC Oral Health and BDJ Open, key journals in the field.

A significant issue with research into use of collection in dentistry, and one which is shared by many other disciplines, is that many journals are popular publication venues and sources of information for dental researchers (e.g., Journal of Bone and Mineral Research), but are not specifically dental journals.

\section{Conclusion}

This project demonstrated that each tool and dataset provided a different picture of the collection and suggested different journals as being "top" or significant. This is critical when using tools for collection development and weeding decisions, as relying on a single tool may provide only one aspect of usage. It is also important when conducting liaison work, such as when learning about the collection and reaching out to faculty and students. While going through the exercise is worth the effort for many collections, one must keep the limitations of each tool in mind. Going forward, more work is needed to correct suspect data as well as to determine usage statistics on open access titles as these are not well captured by these tools. Also, the McGill Library will need to review journal titles that were mentioned by the faculty as important but to which the library does not have full access.

-Copyright 2019 Joseph Hafner, Dawn McKinnon, Martin Morris, and Andrew Senior 


\section{Notes}

1. John D. McDonald, "Understanding Journal Usage: A Statistical Analysis of Citation and Use," Journal of the American Society for Information Science and Technology 58, no. 1 (2007): 39; Joanna Duy et al., "Can Electronic Journal Usage Data Replace Citation Data as a Measure of Journal Use? An Empirical Examination," Journal of Academic Librarianship 32, no. 5 (2006): 516.

2. Deborah D. Blecic et al., "Measures of Health Sciences Journal Use: A Comparison of Vendor, Linkresolver, and Local Citation Statistics," Journal of the Medical Library Association: JMLA 101, no. 2 (2013): 110-119.

3. Blecic et al., "Measures of Health Sciences Journal Use"; Rusty Kimball et al., "A Citation Analysis of Atmospheric Science Publications by Faculty at Texas A\&M University," College \& Research Libraries 74, no. 4 (2013): 356-367; Wical et al., "Notes on Operations: Combining Citation Studies and Usage Statistics to Build a Stronger Collection," Library Resources \& Technical Services 59, no. 1 (2015): 33-42.

4. Chew et al., "E-Journal Metrics for Collection Management: Exploring Disciplinary Usage Differences in Scopus and Web of Science." Evidence Based Library and Information Practice 11, no. 2 (2016): 97-120.

5. "Enrolment Report Fall 2018: Total (FT and PT) Enrolments by Level and by Faculty," McGill University, accessed January 10, 2019, https://www.mcgill.ca/es/files/es/fall_2018__total_ft_and_pt_enrolments_by_level_and_by_faculty.pdf.

6. R Core Team, R: A Language and Environment for Statistical Computing, R Foundation for Statistical Computing, Vienna, Austria, 2013, http://www.R-project.org.

7. RStudio Team, RStudio: Integrated Development for R, RStudio, Inc., Boston, MA, 2015, http://www.rstudio.com. 